\title{
C-Reactive Protein Gene Polymorphisms Correlated with Serum CRP Levels of Diesel Engine Exhaust-Exposed Workers
}

\author{
Liping Zhang1,2*, Huawei Duan1, Xiaomei Zheng', Ping Bin'1, Yuxin Zheng ${ }^{1,3^{*}}$ \\ ${ }^{1}$ Key Laboratory of Chemical Safety and Health, National Institute for Occupational Health and Poison Control, Chinese Center \\ for Disease Control and Prevention, Beijing, China \\ ${ }^{2}$ Weifang Medical University, Weifang, China \\ ${ }^{3}$ School of Public Health, Qingdao University, Qingdao, China \\ Email: *yx_zheng@139.com
}

How to cite this paper: Zhang, L.P., Duan, H.W., Zheng, X.M., Bin, P. and Zheng, Y.X. (2020) C-Reactive Protein Gene Polymorphisms Correlated with Serum CRP Levels of Diesel Engine Exhaust-Exposed Workers. Health, 12, 629-637.

https://doi.org/10.4236/health.2020.126047

Received: May 10, 2019

Accepted: June 21, 2020

Published: June 24, 2020

Copyright $\odot 2020$ by author(s) and Scientific Research Publishing Inc. This work is licensed under the Creative Commons Attribution International License (CC BY 4.0).

http://creativecommons.org/licenses/by/4.0/

\section{Open Access}

\begin{abstract}
Objective: To assess the association between circulating C-reactive protein (CRP), and CRP polymorphisms in the diesel engine exhaust (DEE)-exposed workers. Methods: In 137 DEE-exposed workers and 127 unexposed comparable control workers, six urinary mono-hydroxylated polycyclic aromatic hydrocarbons (OH-PAHs) and serum CRP levels were assayed. Genotyping of four CRP single-nucleotide polymorphisms (SNPs) was measured. Results: Serum CRP levels increased in exposed versus control workers (all $\mathrm{p}<0.001$ ). In the DEE-exposed workers, two CRP polymorphisms were associated with serum CRP levels, the subjects of rs1205 TT genotype had lower serum CRP levels ( $\mathrm{p}<0.05$ compared to TC or CC). Conclusions: Our findings suggest that polymorphisms in CRP and circulating CRP involved in the inflammatory process may play significant roles in human sensitivity to lung function injury caused by DEE exposure. This study will help investigate the underlying mechanisms of adverse respiratory effects induced by DEE.
\end{abstract}

\section{Keywords}

Diesel Engine Exhaust, C-Reactive Protein, Single-Nucleotide

Polymorphisms, Long-Term Exposure

\section{Introduction}

Diesel engines that produce diesel engine exhaust (DEE) are used for road and off-highway transportation and (heavy) equipment in various industries. DEE is a complex mixture of gaseous components and particles, with mutagenic and 
carcinogenic compounds adsorbed to a carbon core [1]. Considering the significant number of urban residents and workers exposed to DEE, there is an increased concern about DEE exposure-related adverse health effects. Because of their small size, diesel particles can be inhaled and a portion will eventually become trapped within the small airways and the alveolar regions of the lung. Epidemiological evidence suggests that DEE exposure is associated with respiratory diseases. Workers exposed to DEE report decreases in lung function [2], and showed an increased mortality from chronic obstructive pulmonary disease (COPD) [3]. Controlled exposure to diesel exhaust results in inflammatory changes within the lung and in peripheral blood [4]. In addition, the International Agency for Research on Cancer classified DEE as a group I carcinogen in 2012 [5].

In general environment, DEE is co-existed with many air pollutions. Therefore, it is hard to identify the effects of DEE from the mixed exposure. Although the underlying toxicological mechanisms by which DEE induces adverse effects on respiratory system are not yet entirely understood, a number of studies suggested that inflammation played a significant role in the mechanism by which DEE may exert toxicity recently [6] [7]. The deposition of fine particles in the lung alveoli can induce local inflammation, then systemic inflammation may be elicited [8]. C-reactive protein (CRP), a marker of systemic inflammation, has been used in some chronic inflammatory diseases [9]. Circulating levels of CRP are known to increase in response to infection and tissue damage. Higher levels of serum CRP were associated with impaired lung function (a lower $\mathrm{FEV}_{1}$ ) in healthy subjects and patients suffering from COPD [10], although there are conflicting results [11]. Epidemiologic and human controlled studies suggest a link between circulating levels of CRP and PM exposure, since the CRP levels of healthy volunteers and women increased after PM exposure [12].

Existing evidence suggests that CRP levels are influenced by both environment and genetic factors. The baseline serum CRP levels are known to be associated with the single nucleotide polymorphisms (SNPs) of the CRP gene [13]. In a cohort study, it was found that rs1205, rs1130864, and rs1800947 SNPs in the CRP gene were related to serum CRP, and there was an association between serum CRP and FEV1 decline; however, no significant associations between the SNPs and lung function were observed in the men [14]. In Chinese subjects, the CRP polymorphism rs2794521 located in the promoter region has been found to be associated with coronary heart disease (CHD) [15]. If higher serum CRP levels reduce lung function, then a CRP polymorphism that was associated with higher levels of serum CRP should also lead to impaired lung function [16].

We previously found that long-term exposure to DEE can induce decline in lung function which shows mainly obstructive changes. However, less is known about the association between lung function parameters, circulating CRP, and CRP polymorphisms in the DEE-exposed workers. In the present study, we examine the association between previously well-studied CRP polymorphisms (rs1205), circulating CRP levels in the DEE-exposed workers. 


\section{Materials and Methods}

\subsection{Study Population and Sample Collection}

The study population was previously described [17]. Briefly, we recruited 137 workers from a diesel engine manufacturing plant as the DEE-exposed group. The DEE-exposed workers tested heavy-duty diesel engines in the engine assembly workshop. We chose 127 workers from a water supply plant in the same city as the control group. The workers of the control group operated the electric powered water pumps. The included workers had to be working in the same area of the factory for at least 1 year, free of acute infection and chronic diseases. Subjects with exposure to X-rays within the last three months were also excluded. As most workers were males, only male workers were included in order to avoid potential confounding from gender. The study was approved by the Research Ethics Committee of the National Institute for Occupational Health and Poison Control, Chinese Center for Disease Control and Prevention, and informed consent was obtained from each participant. All participants were interviewed by occupational physicians using a detailed questionnaire that included demographic information, smoking history, alcohol consumption, occupational history of exposure, and personal medical history. Finally, at the end of shift after at least 4 consecutive working days, peripheral blood samples were collected from each subject for the extraction of DNA and serum separation used for CRP measurement. A spot urine sample was obtained from each subject and used for the detection of mono-hydroxylated PAHs (OH-PAHs).

\subsection{Measurement of Urinary Mono-Hydroxylated PAHs (OH-PAHs)}

Six urinary $\mathrm{OH}-\mathrm{PAHs}$, including 1-hydroxynaphthalene (1-OHNa), 2-hydroxynaphthalene (2-OHNa), 2-hydroxyfluorene (2-OHFlu), 2-hydroxyphenanthrene (2-OHPh), 9-hydroxyphenanthrene (9-OHPh), and 1-hydroxypyrene (1-OHP) were detected using the HPLC-MS/MS method as described previously [18].

\subsection{Measurement of Serum CRP Levels}

The serum levels of CRP were measured using the Human C-Reactive Protein/CRP Quantikine ELISA Kit (R \& D System, Inc. Minneapolis, USA) according to the manufacturer's instructions. The detectable levels of CRP ranged from $0.005-0.022 \mathrm{ng} / \mathrm{mL}$. All assays were performed on the BioTek ELx800 microplate reader (BioTek, Winooski, VT). All samples were measured in triplicate, and values were averaged for analysis.

\subsection{DNA Isolations and Genotype Determination}

Six Human genomic DNA was extracted from stored EDTA-anticoagulated whole blood using the TIANamp Blood DNA Kit (Tiangen Biotech, Beijing, China) according to the manufacturer's specifications. After quantification using 
a Nanodrop 2000 spectrophotometer (Thermo Scientific, MA, USA) to determine the concentration and purity, we excluded 11 samples without qualified concentration and purity. Eventually, 132 DEE-exposed workers and 121 controls were included in the analysis. Based on information in the 1000 Genomes Project data and the NCBI SNP database for the Han Chinese population, previously published SNPs with a minor allele frequency $>5 \%$ were selected for the study, including rs1205 in the 3'flanking region [15]. Genotyping for rs1205 was conducted using TaqMan SNP Genotyping Assays (rs1205: C_7479334_10, Life Technologies, CA, USA). The standard $5 \mu \mathrm{L}$ PCR reaction system (including $5 \mathrm{ng}$ of genomic DNA template) was prepared using TaqMan Universal PCR Master Mix reagent kits under the guidelines provided. Thermal cycling reactions were performed as follows: $95^{\circ} \mathrm{C}$ for $10 \mathrm{~min}$, and then 40 cycles at $95^{\circ} \mathrm{C}$ for $15 \mathrm{~s}$ and $60^{\circ} \mathrm{C}$ for $1 \mathrm{~min}$. Amplifications were carried out on the ABI 7900HT Fast Real-Time PCR System. A total of $10 \%$ of samples were re-genotyped for each SNP at random as genotyping quality control, and all results were consistent. In addition, all DNA samples for the DEE-exposed workers and controls were evaluated blindly in the same batches. Negative water controls were included for each experiment.

\subsection{Statistical Analysis}

Urinary $\mathrm{OH}-\mathrm{PAH}$ concentrations were natural logarithmic transformed to satisfy the normal distribution. Total OH-PAHs levels were calculated by summing urinary levels of six OH-PAHs. Statistical comparisons of quantitative data (age, height, weight, BMI, urinary $\mathrm{OH}-\mathrm{PAH}$ concentrations, and lung function parameters) were performed using Student $t$ test between various groups and using Chi-square test for the frequencies of qualitative data (current smokers and alcohol users). Serum CRP levels were compared between groups by Mann-Whitney test. The deviation from Hardy-Weinberg equilibrium for genotype frequencies and genotype and allele frequencies between groups were compared by Chi-square test. In the DEE-exposed workers and controls, respectively, the associations of CRP genotypes with the serum CRP levels (natural logarithmic transformed) were analyzed by Student t-test and multivariable linear regression analysis adjusted for urinary total OH-PAHs, age, BMI, smoking and alcohol drinking. All statistical analyses were performed with SPSS 15.0 software (SPSS Inc, Chicago, USA), and $\mathrm{p}<0.05$ was considered statistically significant.

\section{Results}

\subsection{General Characteristics, Serum CRP Levels, and DEE Exposure Levels}

Subject's characteristics and serum CRP levels are shown in Table 1. The DEE-exposed workers and the controls did not significantly differ in terms of the average age, height, weight, BMI, current smoking habits, and alcohol use. Most of the DEE-exposed workers were exposed long term to DEE with an average 
Table 1. The characteristics, urinary total OH-PAHs concentration, and serum CRP levels of the DEE-exposed workers and controls.

\begin{tabular}{|c|c|c|c|}
\hline \multirow{2}{*}{ Variable } & Controls & DEE-exposed workers & \multirow{2}{*}{$P$ value } \\
\hline & $(\mathrm{n}=121)$ & $(\mathrm{n}=132)$ & \\
\hline Age $(\mathrm{yr}$, mean $\pm \mathrm{SD})$ & $31.93 \pm 11.11$ & $31.85 \pm 8.60$ & $0.95^{\star}$ \\
\hline Height $(\mathrm{cm}$, mean $\pm \mathrm{SD})$ & $171.03 \pm 5.87$ & $171.42 \pm 5.42$ & $0.586^{\star}$ \\
\hline Weight $(\mathrm{kg}$, mean $\pm \mathrm{SD})$ & $69.78 \pm 14.19$ & $72.42 \pm 10.60$ & $0.093^{*}$ \\
\hline $\mathrm{BMI}\left(\mathrm{kg} / \mathrm{m}^{2}\right.$, mean $\left.\pm \mathrm{SD}\right)$ & $23.83 \pm 4.49$ & $24.64 \pm 3.41$ & $0.106^{\star}$ \\
\hline Current smokers, yes/no (\% yes) & $57 / 64(47.1)$ & $78 / 54(59.1)$ & $0.060^{\dagger}$ \\
\hline Alcohol use, yes/no (\% yes) & $79 / 42(65.3)$ & $87 / 45(65.9)$ & $1.000^{\dagger}$ \\
\hline DEE exposure years (year, mean \pm SD) & - & $8.18 \pm 5.20$ & - \\
\hline $\begin{array}{c}\text { Total OH-PAHs } \\
(\mu \mathrm{g} / \mathrm{g} \text { creatinine, median, } 5 \%-95 \%)^{\S}\end{array}$ & $4.68(0.98-15.02)$ & $12.72(4.43-33.66)$ & $<0.001^{\star}$ \\
\hline CRP (mg/L, median, 5\% - 95\%) & $0.38(0.06-6.23)$ & $0.84(0.30-5.06)$ & $<0.001^{*}$ \\
\hline
\end{tabular}

${ }^{*}$ Student t-test. ${ }^{\varsigma}$ Natural logarithmic transformed total OH-PAHs. ${ }^{\dagger}$ Chi square test. ${ }^{*}$ Mann-Whitney U test. DEE, diesel engine exhaust; BMI, body mass index; CRP, C-reactive protein; OH-PAHs, mono-hydroxylated polycyclic aromatic hydrocarbons.

duration of 8.18 years. Urinary OH-PAHs are representative of internal PAH and DEE exposure. The median of urinary total OH-PAHs ( $\mu \mathrm{g} / \mathrm{g}$ creatinine) in the DEE-exposed workers was 2.72 -fold higher than that of controls (12.72 vs. $4.68, \mathrm{p}<0.001)$. The levels of serum CRP were significantly increased in the DEE-exposed workers $(\mathrm{p}<0.001)$.

\subsection{CRP Genotypes Correlated with Serum CRP Levels in the DEE-Exposed Workers}

The variant allele frequency of CRP at loci rs 1205 was 0.597 , in the 253 subjects. The distributions of all this polymorphism was consistent with Hardy-Weinberg equilibrium $(\mathrm{p}=0.579)$. There were no significant differences in genotype distributions between the DEE-exposed workers and control workers. The associations of CRP genotypes with the serum CRP levels were analyzed by Student t-test and multivariable linear regression analysis adjusted for urinary total $\mathrm{OH}-\mathrm{PAHs}$, age, BMI, smoking and alcohol drinking, and is presented in Table 2.

Results from two kinds of analysis showed similar results. Multivariable linear regression analysis with adjustment for urinary total OH-PAHs, age, BMI, smoking and alcohol drinking revealed that among the DEE-exposed workers, the CRP rs1205 CC or TC genotype carriers exhibited significantly higher serum CRP levels (median, $0.87 \mathrm{mg} / \mathrm{L}$ for CC and $0.88 \mathrm{mg} / \mathrm{L}$ for TC) than the TT genotype carriiers (median, $0.72 \mathrm{mg} / \mathrm{L})(\mathrm{p}=0.011$ and $\mathrm{p}=0.004$, respectively). No such associations were observed in the controls (Table 2).

Results from two kinds of analysis showed similar results. Multivariable linear regression analysis with adjustment for urinary total OH-PAHs, age, BMI, smoking 
Table 2. Effects of CRP genotypes on serum CRP levels of the DEE-exposed workers and controls.

\begin{tabular}{|c|c|c|c|c|c|c|c|c|}
\hline \multirow[b]{3}{*}{ Variable } & \multicolumn{8}{|c|}{$\mathrm{CRP}(\mathrm{mg} / \mathrm{L})$} \\
\hline & \multicolumn{4}{|c|}{ Controls $(\mathrm{n}=121)$} & \multicolumn{4}{|c|}{ DEE-exposed workers $(n=132)$} \\
\hline & $\mathrm{N}$ & $\begin{array}{c}\text { Median } \\
(5 \%-95 \%)\end{array}$ & $P$ value ${ }^{*}$ & P value $^{\dagger}$ & $\mathrm{N}$ & $\begin{array}{c}\text { Median } \\
(5 \%-95 \%)\end{array}$ & $P$ value ${ }^{\star}$ & $\mathrm{P}_{\text {value }}^{\dagger}$ \\
\hline \multicolumn{9}{|l|}{ rs1205 } \\
\hline $\mathrm{TT}^{\ddagger}$ & 42 & $\begin{array}{c}0.33 \\
(0.06-5.82)\end{array}$ & & & 46 & $\begin{array}{c}0.72 \\
(0.32-1.70)\end{array}$ & & \\
\hline TC & 55 & $\begin{array}{c}0.41 \\
(0.07-0.64)\end{array}$ & 0.613 & 0.846 & 71 & $\begin{array}{c}0.88 \\
(0.28-5.64)\end{array}$ & 0.018 & 0.004 \\
\hline $\mathrm{CC}$ & 24 & $\begin{array}{c}0.55 \\
(0.04-6.58)\end{array}$ & 0.348 & 0.660 & 15 & $\begin{array}{c}0.87 \\
(0.20-)\end{array}$ & 0.027 & 0.011 \\
\hline
\end{tabular}

${ }^{*}$ Student $\mathrm{t}$-test. ${ }^{\dagger}$ Multivariable linear regression analysis with adjustment for urinay total OH-PAHs, age, BMI, smoking and alcohol drinking. ${ }^{*}$ Reference group for comparisons of natural logarithmic transformed serum CRP levels between genotypes. DEE, diesel engine exhaust; CRP, C-reactive protein.

and alcohol drinking revealed that among the DEE-exposed workers, the CRP rs1205 CC or TC genotype carriers exhibited significantly higher serum CRP levels (median, $0.87 \mathrm{mg} / \mathrm{L}$ for CC and $0.88 \mathrm{mg} / \mathrm{L}$ for TC) than the TT genotype carriers (median, $0.72 \mathrm{mg} / \mathrm{L})(\mathrm{p}=0.011$ and $\mathrm{p}=0.004$, respectively). No such associations were observed in the controls (Table 2).

\section{Discussion}

The exact causal connection between air pollution including DEE and adverse health effects is still not fully understood. CRP is considered to be one of the most frequently used markers of inflammation, and higher levels of CRP in peripheral blood may cause impaired lung function [17]. However, no population study has yet examined whether increased serum CRP levels induced by DEE exposure is associated with CRP polymorphisms. To the best of our knowledge, the present report is the first study so far that examines the associations of serum CRP levels and the CRP polymorphisms in an exclusively DEE-exposed occupational population.

For DEE exposure, we found that the serum CRP levels were increased in the DEE-exposed workers compared to the controls. However, our results are inconsistent with some controlled DEE chamber studies reflecting the acute effect of DEE on serum CRP in healthy volunteers [19] [20], which did not find a DEE-associated increase in CRP. There are few reported studies of the association between serum CRP concentration and chronic exposure to DEE. A study reported that the increase in PM2.5 was associated with the increase levels of serum hs-CRP in traffic policemen [21], which was in line with our results. CRP concentrations in blood are extremely low in healthy individuals, but may be rapidly increased after induction of inflammatory response associated with infections and cardiovascular diseases, as well as cancer. Taken together, our data and previous observations suggested that serum CRP, a biomarker of systemic in- 
flammation, may play a key role in lung function decline induced by long-term exposure to DEE.

The expression of CRP is genetically conditioned. The relationship between particular SNP allele (variants) and diverse CRP expression was demonstrated [22]. Our results also exhibit a robust association between serum CRP levels and CRP polymorphisms. In the DEE-exposed workers, the polymorphisms rs1205 were found to be associated with serum CRP levels. There is now ample direct evidence that some CRP gene polymorphisms affect the amount of CRP produced. In the present study, the CRP rs1205 CC genotype carriers exhibited significantly higher serum CRP levels than the TT genotype carriers exhibited significantly higher serum CRP levels than the GG genotype carriers. Our observation was also in agreement with the previous finding that in all subjects (patients with atrial fibrillation and the controls) of a Han Chinese population, the minor alleles of rs1205 and rs3091244 were significantly associated with higher CRP levels [23].

The gene-environment interaction is a major risk factors for a number of diseases in humans. Gene-environment studies are of special interest in the examination of lung injury induced by DEE. Our recently results show that long-term exposure to DEE can induce decline in lung function which shows mainly obstructive changes. In the current study, we observed that CRP polymorphisms rs1205were associated with increase in serum CRP levels among DEE-exposed workers, whereas no such associations were found among the control workers. This suggests the importance of gene-environment interaction.

\section{Summary}

In summary, our findings suggest that polymorphisms in CRP and circulating CRP involved in the inflammatory process, may play significant roles in human sensitivity to lung function injury caused by DEE exposure. This study will help investigate the underlying mechanisms of adverse respiratory effects induced by DEE. However, prospective studies with a larger sample size that employ cumulative DEE exposure are needed to replicate and extend these findings, and to further evaluate other potential mechanisms of DEE biological action.

\section{Acknowledgements}

The authors would like to thank the members of the Henan Institute of Occupational Medicine (Zhengzhou, China) for assistance with sample collection and instrumental support. This study was supported by a National Natural Science Foundation of China (NSFC 81130050), and a National Key Technology Research and Development Program (2014BAI12B02).

\section{Conflicts of Interest}

The authors declare no conflicts of interest regarding the publication of this paper. 


\section{References}

[1] Kittelson, D., Watts, W., Ramachandran, G., Paulsen, D. and Kreager, C. (2002) Measurement of Diesel Aerosol Exposure: A Feasibility Study. In: Diesel Epidemiology Working Group, Ed., Research Directions to Improve Estimates of Human Exposure and Risk from Diesel Exhaust, Health Effects Institute, Boston, 151-179.

[2] Ulvestad, B., Bakke, B., Melbostad, E., Fuglerud, P., Kongerud, J. and Lund, M.B. (2000) Increased Risk of Obstructive Pulmonary Disease in Tunnel Workers. Thorax, 55, 277-282.

[3] Hart, J.E., Laden, F., Eisen, E.A., Smith, T.J. and Garshick, E. (2009) Chronic Obstructive Pulmonary Disease Mortality in Railroad Workers. Occupational and Environmental Medicine, 66, 221-226.

[4] Salvi, S., Blomberg, A., Rudell, B., Kelly, F., Sandstrom, T., Holgate, S.T. and Frew, A. (1999) Acute Inflammatory Responses in the Airways and Peripheral Blood after Short-Term Exposure to Diesel Exhaust in Healthy Human Volunteers. American Journal of Respiratory and Critical Care Medicine, 159, 702-709. https://doi.org/10.1164/ajrccm.159.3.9709083

[5] (2012) IARC: Diesel Engine Exhaust Carcinogenic. Central European Journal of Public Health, 20, 120, 138.

[6] Ayres, J. G., Borm, P., Cassee, F.R., Castranova, V., Donaldson, K., Ghio, A., et al. (2008) Evaluating the Toxicity of Airborne Particulate Matter and Nanoparticles by Measuring Oxidative Stress Potential-A Workshop Report and Consensus Statement. Inhalation Toxicology, 20, 75-99. https://doi.org/10.1080/08958370701665517

[7] Donaldson, K., Tran, L., Jimenez, L.A., Duffin, R., Newby, D.E., Mills, N., et al. (2005) Combustion-Derived Nanoparticles: A Review of Their Toxicology Following Inhalation Exposure. Particle and Fibre Toxicology, 2, Article No.: 10. https://doi.org/10.1186/1743-8977-2-10

[8] Polichetti, G., Cocco, S., Spinali, A., Trimarco, V. and Nunziata, A. (2009) Effects of Particulate Matter $\left(\mathrm{PM}_{10}, \mathrm{PM}_{2.5}\right.$ and $\left.\mathrm{PM}_{1}\right)$ on the Cardiovascular System. Toxicology, 261, 1-8. https://doi.org/10.1016/j.tox.2009.04.035

[9] Rasmussen, F., Mikkelsen, D., Hancox, R.J., Lambrechtsen, J., Nybo, M., Hansen, H. S. and Siersted, H.C. (2009) High-Sensitive C-Reactive Protein Is Associated with Reduced Lung Function in Young Adults. European Respiratory Journal, 33, 382-388. https://doi.org/10.1183/09031936.00040708

[10] Eid, A.A., Ionescu, A.A., Nixon, L.S., Lewis-Jenkins, V., Matthews, S.B., Griffiths, T.L. and Shale, D.J. (2001) Inflammatory Response and Body Composition in Chronic Obstructive Pulmonary Disease. American Journal of Respiratory and Critical Care Medicine, 164, 1414-1418. https://doi.org/10.1164/ajrccm.164.8.2008109

[11] Fogarty, A.W., Jones, S., Britton, J.R., Lewis, S.A. and McKeever, T.M. (2007) Systemic Inflammation and Decline in Lung Function in a General Population: A Prospective Study. Thorax, 62, 515-520.

[12] Chuang, K.-J., Chan, C.-C., Su, T.-C., Lee, C.-T. and Tang, C.-S. (2007) The Effect of Urban Air Pollution on Inflammation, Oxidative Stress, Coagulation, and Autonomic Dysfunction in Young Adults. American Journal of Respiratory and Critical Care Medicine, 176, 370-376.

https://www.atsjournals.org/doi/full/10.1164/rccm.200611-1627OC https://doi.org/10.1164/rccm.200611-1627OC

[13] Siemes, C., Visser, L.E., Coebergh, J.-W.W., Splinter, T.A., Witteman, J.C., Uitterlinden, A.G., et al. (2006) C-Reactive Protein Levels, Variation in the C-Reactive Protein Gene, and Cancer Risk: The Rotterdam Study. Journal of Clinical Oncology, 


\section{4, 5216-5222. https://doi.org/10.1200/JCO.2006.07.1381}

[14] Bolton, C.E., Schumacher, W., Cockcroft, J.R., Timpson, N.J., Smith, G.D., Gallacher, J., et al. (2011) The CRP Genotype, Serum Levels and Lung Function in Men: The Caerphilly Prospective Study. Clinical Science, 120, 347-355. https://doi.org/10.1042/CS20100504

[15] Chen, J., Zhao, J., Huang, J., Su, S., Qiang, B. and Gu, D. (2005) -717A>G Polymorphism of Human C-Reactive Protein Gene Associated with Coronary Heart Disease in Ethnic Han Chinese: The Beijing Atherosclerosis Study. Journal of molecular medicine, 83, 72-78. https://doi.org/10.1007/s00109-004-0585-5

[16] Carlson, C.S., Aldred, S.F., Lee, P.K., Tracy, R.P., Schwartz, S.M., Rieder, M., et al. (2005) Polymorphisms within the C-Reactive Protein (CRP) Promoter Region Are Associated with Plasma CRP Levels. The American Journal of Human Genetics, 77, 64-77. https://doi.org/10.1086/431366

[17] Zhang, L.P., Zhang, X., Duan, H.W., Meng, T., Niu, Y., Huang, C.F., et al. (2017) Long-Term Exposure to Diesel Engine Exhaust Induced Lung Function Decline in a Cross Sectional Study. Industrial Health, 55, 13-26.

[18] Zhang, X., Duan, H., Gao, F., Li, Y., Huang, C., Niu, Y., et al. (2015) Increased Micronucleus, Nucleoplasmic Bridge, and Nuclear Bud Frequencies in the Peripheral Blood Lymphocytes of Diesel Engine Exhaust-Exposed Workers. Toxicological Sciences, 143, 408-417. https://doi.org/10.1093/toxsci/kfu239

[19] Carlsten, C., Kaufman, J.D., Peretz, A., Trenga, C.A., Sheppard, L. and Sullivan, J. H. (2007) Coagulation Markers in Healthy Human Subjects Exposed to Diesel Exhaust. Thrombosis Research, 120, 849-855. https://doi.org/10.1016/j.thromres.2007.01.005

[20] Xu, Y., Barregard, L., Nielsen, J., Gudmundsson, A., Wierzbicka, A., Axmon, A., et al. (2013) Effects of Diesel Exposure on Lung Function and Inflammation Biomarkers from Airway and Peripheral Blood of Healthy Volunteers in a Chamber Study. Particle and fibre toxicology, 10, Article No.: 60. https://doi.org/10.1186/1743-8977-10-60

[21] Zhao, J., Gao, Z., Tian, Z., Xie, Y., Xin, F., Jiang, R., et al. (2013) The Biological Effects of Individual-Level PM2. 5 Exposure on Systemic Immunity and Inflammatory Response in Traffic Policemen. Occupational and Environmental Medicine, 70, 426-431.

[22] Kathiresan, S., Larson, M.G., Vasan, R.S., Guo, C.Y., Gona, P., Keaney Jr., J.F., et al. (2006) Contribution of Clinical Correlates and 13 C-Reactive Protein Gene Polymorphisms to Interindividual Variability in Serum C-Reactive Protein Level. Circulation, 113, 1415-1423. https://doi.org/10.1161/CIRCULATIONAHA.105.591271

[23] Tung, Y.C., Wu, L.S., Chen, W.J., Kuo, C.T., Wang, C.L., Chang, C.J., et al. (2013) C-Reactive Protein Gene Polymorphisms and the Risk of Atrial Fibrillation in a Chinese Population in Taiwan. Acta Cardiologica Sinica, 29, 208. 